\title{
Perceived and Actual Knowledge of Cupping Therapy Concepts among Athletic Training Preceptors in CAATE Accredited Programs
}

ISSN: 2577-1914

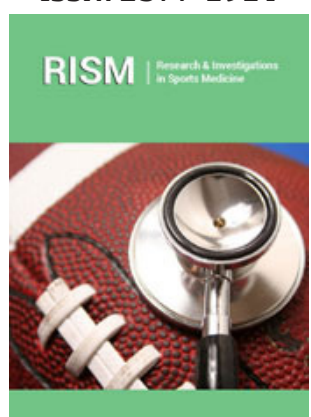

*Corresponding author: Cage SA, University of Texas at Tyler, University of North Carolina, USA

Submission: 制 April 24, 2020

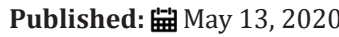

Volume 6 - Issue 3

How to cite this article: Cage $\mathrm{SA}$ Warner BJ, Gallegos DM, Winkelmann ZK. Perceived and Actual Knowledge of Cupping Therapy Concepts among Athletic Training Preceptors in CAATE Accredited Programs. Res Inves Sports Med, 6(3): RISM.000638. 2020. DOI: $10.31031 /$ RISM.2020.06.000638

Copyright@ Cage SA, This article is distributed under the terms of the Creative Commons Attribution 4.0 International License, which permits unrestricted use and redistribution provided that the original author and source are credited.

\author{
Cage $\mathrm{SA}^{1,2 *}$, Warner $\mathrm{BJ}^{2,3}$, Gallegos $\mathrm{DM}^{1}$ and Winkelmann $\mathrm{ZK}^{4}$ \\ ${ }^{1}$ University of Texas at Tyler, USA \\ ${ }^{2}$ University of North Carolina, Greensboro \\ ${ }^{3}$ Grand Canyon University, USA \\ ${ }^{4}$ University of South Carolina, USA
}

\begin{abstract}
To date, there does not appear to be a study published that has examined the clinical usage and perceived and actual knowledge of cupping therapy among preceptors for athletic training education programs. A previous study suggested that the majority of athletic trainers use cupping therapy to some extent in their clinical practice, but exhibited a gap in perceived and actual knowledge. However, the study did not examine athletic training preceptors as a specific population. Thus, the purpose of this study was to determine the perceived and actual knowledge of cupping therapy among athletic training preceptor working with accredited athletic training education programs. A total of 102 athletic trainers who serve as preceptors participated in this study (age $=35 \pm 11$ years, certified experience $=12 \pm 9$ years). Participants were sent an electronic survey by email that assessed frequency of usage, perceived knowledge, and actual knowledge of cupping therapy. Measures of central tendency (means, standard deviations, frequencies) were calculated for all survey items. Data was downloaded and analyzed using a commercially available statistics package (SPSS Version 26, IBM, Armonk, NY). The majority of preceptors reported that cupping therapy was a necessary skill for their clinical practice. Additionally, the majority of participants also reported using cupping therapy at least once during a typical week of clinical practice. Regarding perceived knowledge, the majority of participants were in the mid-range of agreement/ disagreement, indicating at least some uncertainty. Average scores on actual knowledge were $9.19 \pm$ 1.68. A negative relationship was found between perceived knowledge and actual knowledge of cupping therapy $(\mathrm{r}=-0.941, \mathrm{P}<0.001)$. However, participants in this study scored higher on average compared to a previous study of actual knowledge of cupping therapy. Considering most athletic trainers reported using cupping therapy and viewing it as a necessary skill, it is important to ensure proper education on the technique is occurring. Further research should be conducted to determine the best method of knowledge transfer regarding cupping therapy.
\end{abstract}

\section{Introduction}

Cupping therapy is a therapeutic modality that has been documented as early as 3300BC [1]. By using various means of suction, cupping therapy is employed by clinicians around the world for the purpose of improving blood flow, decreasing pain, increasing range of motion, and increasing function [2-4]. In the $21^{\text {st }}$ century, cupping therapy has grown in popularity in the United States and other countries where Western Medicine is practiced [1]. A large amount of this popularity is likely due to increased media interest resulting from elite level athletes receiving cupping therapy $[5,6]$. Although cupping therapy has increased in popularity as a treatment option in the United States, there is still no consensus on the ideal parameters for prescribing and applying cupping therapy to either amateur or professional athletes [1]. This lack of consensus can be attributed in part to a lack of high quality studies and a lack of standardized methodology [4,7]. Another potential factor may be skepticism of Eastern Medicine practices in countries that practice primarily Western Medicine [7].

There are a several theories regarding how cupping therapy achieves its effects. Cupping therapy has been shown to have a positive effect on local and regional blood flow $[3,8,9]$. 
During a cupping therapy treatment, the treated tissues undergo negative pressure that results in compression of the tissues in contact with the rim of the cup and distraction of the tissues within the cup. The amount of compression and distraction that occurs is determined by the amount of suction exerted by the cup. This lower pressure within the cup is suggested to cause a pressure differential between the skin within the cup and underlying capillaries [10]. When exposed to this change in pressure, blood vessels vasodilate, which causes localized increased blood flow at the treatment site [10]. This increase in blood flow may result in the pain reduction demonstrated in previous studies [11]. Aside from increasing blood flow, cupping therapy may reduce pain through other mechanisms. Lowe reported that while the body is healing the circular marks left by cupping therapy, white blood cells are attracted to the area and the enzyme heme oxygenase-1 (HO-1) is produced [11]. As the body breaks down HO-1, the bi products include: heme, biliverdin, bilirubin, carbon monoxide, and iron [11]. During this process, the iron is sequestered by ferritin and the other biproducts have direct and indirect effects that may create a better environment for healing at the treatment site [11].

In the athletic training profession, cupping therapy has grown in popularity in recent years. Researchers have begun examining the uses for cupping therapy for treating athletic populations [1]. In spite of this trend, there has appears to only be one study that has examined the prevalence of clinical use and the perceived and actual knowledge of cupping therapy among athletic trainers [12]. Further information on this topic would have potential value for athletic training educators attempting to prepare lessons or continuing education programs. The purpose of this study was to determine the perceived and actual knowledge of cupping therapy among athletic trainers serving as preceptors for accredited athletic training education programs.

\section{Methods}

\section{Design}

This study was conducted using a cross-sectional design utilizing an internet-based survey for data collection.

\section{Participants}

Participants were recruited for this study by emailing the program directors for accredited athletic training education programs that were listed as being in good standing with the Commission for the Accreditation of Athletic Training Education (CAATE). Program directors were asked to distribute an email containing an explanation of the study and a link to the survey to the athletic trainers serving as preceptors for their programs. A total of 337athletic trainers were emailed. 102 participants (age $=35 \pm 11$ years, years of certified experience $=12 \pm 9$ years) opened the survey link and completed the instrument (access and completion rates $=30.3 \%$ ). Demographic information regarding the participants is presented in Table 1. All participants were informed of the survey's purpose as part of the beginning of the survey, at which point informed consent was obtained per the protocol approved by the University of Texas at Tyler Institutional Review Board.

Table 1: Totals and percentage for participant demographic information.

\begin{tabular}{|c|c|c|}
\hline Demographic Factor & Criteria & Responses \\
\hline Sex & Male Female & $52,51 \% 50,49 \%$ \\
\hline \multirow{3}{*}{ Clinical Practice Setting } & College/University & $73,71.6 \%$ \\
& Secondary School & $22,21.6 \%$ \\
& Professional Sports & $3,2.9 \%$ \\
& Clinic/Hospital & $2,2 \%$ \\
& Emerging Settings & $2,2 \%$ \\
Highest Degree Earned & Professional Bachelor's & $17,16.7 \%$ \\
& Professional Master's & $43,42.2 \%$ \\
& Post-Professional Masters (in Athletic Training) & $16,15.7 \%$ \\
& Post-Professional Master's (not in Athletic Training) & $21,20.6 \%$ \\
\hline
\end{tabular}

\section{Data collection}

An email was sent to the program directors of CAATE accredited programs that were listed as "in good standing". The message was then forwarded to all prospective participants inviting them to participate in an electronic survey via a hyperlink from a webbased server (Qualtrics Inc., Provo, UT) from April to May 2020. The inviting message contained information about the investigators, the purpose of the study, the nature of the survey, and assurances that the participants could opt to not complete the survey at any time. A follow-up email was sent to program directors a week after the initial email and left opens for a week prior to the survey being closed for statistical analysis. 


\section{Instrument}

Following the informed consent and demographics section, the instrument contained items related to formal education and training regarding cupping therapy, as well as the frequency of usage for cupping therapy during typical clinical practice. Participants were also asked to provide information regarding the materials they used when performing cupping therapy.

The perceived knowledge items were adopted and adapted from the Flynn and Goldsmith tool for perceived knowledge. Additionally, five items were added related to the participant's competency with prescribing and applying cupping therapy appropriately. Participants were given statements to read and then asked to answer using a scare from "strongly agree" (1) to "strongly disagree" (7).

For the development of the questions assessing actual knowledge of cupping therapy, a review of recent literature was performed to inform the content $[3,4,9]$. This content was designed to be similar to questions given to athletic training students in a therapeutic modalities class. These questions were developed by a researcher with content expertise and experience creating surveybased research.

Ultimately, the survey consisted of 28 questions. These questions included: one question regarding informed consent, three multiple choice and two fill in the blank questions on demographics, six multiple choice and two multiple answer questions on education and current usage of cupping therapy, 10 Likert-scale items that assessed participants' perceived knowledge, and 10 multiple choice and two multiple answer questions that evaluated participants' actual knowledge.

\section{Statistical analysis}

Information from participant responses was downloaded and analyzed using a commercially-available statistics package (SPSS Version 26, IBM, Armonk, NY). Of the 337 preceptors who received the survey, 102 completed responses were included in the data analysis. Measures of central tendency (means, standard deviations, frequencies) were calculated where appropriate. The researchers reverse scored four items of the perceived knowledge questionnaire and calculated a mean score for the 10 items. Additionally, the researchers calculated a total correct score per participant on the actual knowledge assessment. A Pearson correlation was calculated for the perceived knowledge mean score and the actual knowledge total score to identify a knowledge gap between what participants believed the knew and what they actually knew. Significance was set at $\mathrm{P}<.05$ a priori.

\section{Results}

\section{Education}

Participants reported a nearly even distribution with 51\% (n $=52)$ stating they had, and $49 \%(n=50)$ reporting they had not received education or instruction on the application of cupping therapy. For those who had received prior education, the most common forms included: peer-to-peer education $(39.2 \%, \mathrm{n}=$ 40 ), personal experience such as reading text books and trial and error $(33.3 \%, \mathrm{n}=34)$, and continuing education through a company or organization $(23.5 \%, \mathrm{n}=24)$. The least common forms of knowledge transfer included: formal coursework in a postprofessional program $(3.9 \%, \mathrm{n}=4)$ or lab sessions at a continuing education conference $(8.8 \%, \mathrm{n}=9)$.

\section{Clinical usage}

Over half of participants $(55.9 \%, \mathrm{n}=57)$ agreed that they felt cupping therapy was a necessary skill for their clinical practice. Conversely, $44.1 \%(n=45)$ felt the skill was not necessary. The participants were also asked to identify what supplies they most commonly utilized when completing cupping therapy. The majority of participants used plastic cups $(65.7 \%, \mathrm{n}=67)$ as compared to silicone $(37.3 \%, \mathrm{n}=38)$ or glass $(9.8 \%, \mathrm{n}=10)$ cups. Most participants reported using massage lotion (55.9\%, $\mathrm{n}=57$ ) as their cupping therapy medium. Most participants either reported to having used cupping therapy for patient care within the last six months $(15.1 \%, \mathrm{n}=35)$ or the last month $(10.8 \%, \mathrm{n}=25)$. Additionally, the majority of participants stated they used cupping therapy at least for at least one to three patient interactions during a typical week $(65.7 \%, n=67)$. Only $34.3 \%(n=35)$ of participants reported to not using cupping therapy at all during a typical week.

\section{Perceived knowledge}

The participants had a mean sum of the perceived knowledge items $(n=10)$ of $3.48 \pm 1.68$ out of 10 . This indicated that most participants were in the mid-range regarding their perceived knowledge of cupping therapy. Frequency count of the most common correct responses is provided in Table 2.

Table 2: Perceived Knowledge assessment most common response.

\begin{tabular}{|c|c|}
\hline \multicolumn{1}{|c|}{ Item } & Most Common Response \\
\hline $\begin{array}{c}\text { I am comfortable with the different types of cupping therapy and what I can and } \\
\text { cannot do as an athletic trainer according to my state practice act. }\end{array}$ & Agree (n=25) and Somewhat Agree (n=25) \\
\hline $\begin{array}{c}\text { I do not feel very knowledgeable about the different techniques of cupping therapy } \\
\text { including dry, wet, moving, flash, herbal, and water cupping. }\end{array}$ & Disagree (n=23) \\
\hline Around my colleagues, I would be considered an “expert" on cupping therapy. & Strongly Disagree (n=30) \\
\hline Compare to most athletic trainers, I know very little about cupping therapy. & Neither Agree nor Disagree (n=25) \\
\hline
\end{tabular}




\begin{tabular}{|c|c|}
\hline $\begin{array}{c}\text { I am able to explain the proposed mechanism of action for cupping therapy. } \\
\text { I understand what injuries are indicated and contraindicated, as well as when in the } \\
\text { healing process it is appropriate for cupping therapy as an intervention. }\end{array}$ & Agree (n=35) \\
\hline $\begin{array}{c}\text { I am unsure of how to perform function and safety inspections of cupping therapy } \\
\text { equipment. }\end{array}$ & Agree (n=36) \\
\hline I am skilled and proficient in the application of cupping therapy. & Agree (n=31) \\
\hline $\begin{array}{c}\text { I am likely to pursue continuing education to improve my knowledge and skills about } \\
\text { cupping therapy. }\end{array}$ & Agree (n=35) \\
\hline $\begin{array}{c}\text { I am unable to describe the physical sensation or patient experience of cupping } \\
\text { therapy to a new patient undergoing cupping therapy. }\end{array}$ & Agree (n=39) \\
\hline
\end{tabular}

\section{Knowledge gap}

We identified a strong negative relationship between perceived knowledge mean scores and actual knowledge total correct sum scores $(r=-0.941, P<.001)$. This suggested that as perceived knowledge of cupping therapy increased, actual knowledge of cupping therapy decreased.

\section{Discussion}

The purpose of this study was to assess the perceived and actual knowledge of cupping therapy among athletic trainers serving as preceptors for CAATE accredited athletic training education programs. A secondary purpose was to determine the frequency of usage of cupping therapy among this population of athletic trainers. Our findings indicate that over half of the participants felt that cupping therapy was a necessary skill for their clinical practice $(55.9 \%, n=57)$. Additionally, the majority of participants reported using cupping therapy at least once during a typical week of clinical practice $(65.7 \%, \mathrm{n}=67)$. In fact, only $34.3 \%(\mathrm{n}=35)$ of athletic trainers surveyed reported never using cupping therapy. These findings suggest that athletic trainers using cupping therapy with an increasing frequency, and are beginning to see the modality as a valuable treatment technique.

While cupping therapy has grown increasingly popular in recent years, athletic trainers appear to be split with regard to their perceived knowledge of the modality [12]. Compared to a previous study that assessed actual knowledge of cupping therapy, the athletic trainers surveyed in this study scored higher on average [12]. However, there was a negative relationship observed between perceived knowledge and actual knowledge of cupping therapy in this study. This information suggests athletic trainers may be unsure about knowledge related to cupping therapy. They may also be using cupping therapy on conditions that may benefit more from other treatment. Given the majority of participants reporting receiving education on cupping therapy, this negative relationship may suggest a case of knowledge and skill deterioration.

Previous research has indicated that clinical skills are subject to deterioration if they are not practiced over time [12,13]. Indeed, some studies have suggested that skills such as cardiopulmonary resuscitation can decrease in as little as six months [13]. On average, athletic trainers are more likely to use cupping therapy on a weekly basis compared to cardiopulmonary resuscitation. Still, there is a potential for knowledge and skill deterioration if the modality is not used regularly. In the absence of clinical practice, continuing education has been shown to be a valuable method of knowledge transfer and retention [14].

These findings may suggest a need to include information about the theory and concepts related to cupping therapy within athletic training curriculums. Should this prove difficult for athletic training education programs, continuing education interventions should be considered for imparting and refreshing knowledge of the definition, modes of action, indications, and contraindications of cupping therapy? When these continuing education interventions are created, they should undergo evaluation and re-evaluation to ensure that they are effective and efficient at improving knowledge of cupping therapy among athletic trainers.

A possible limitation of this study was the number of participants. However, this is a similar limitation that other survey based studies on athletic trainers have encountered, and may affect the generalizability of the results when looking to analyze across the profession [12-14]. Additionally, the response and completion rate was higher than some survey based studies on athletic trainers [12]. This study substantiates the assertions of previous research that a need for further research on the perceived knowledge of cupping therapy and therapeutic modalities in general among athletic trainers [12]. To the authors' knowledge, this is only the second study to examine the perceived and actual knowledge of cupping therapy among athletic trainers [12]. Future research should also be directed towards knowledge deterioration related to cupping therapy and other therapeutic modalities.

\section{Conclusion}

In conclusion, cupping therapy is an increasingly popular modality being used by athletic trainers. However, the participants in this study appeared to be split regarding their views of their perceived knowledge of the modality. Even though the average scores for actual knowledge of cupping therapy was higher than scores in a previous study, there was a negative relationship between perceived and actual knowledge of cupping therapy. Given that continuing education has been suggested as a means of knowledge acquisition and retention, clinicians might benefit from creation of continuing education interventions on cupping therapy. 


\section{References}

1. Bridgett R, Mas D, Prac C, Klose P, Duffield R, et al. (2018) Effects of cupping therapy in amateur and professional athletes: Systematic review of randomized controlled trials. J Altern Complement Med 24(3): 208-219.

2. Cage SA, Warner BJ, Gallegos DM, Sims-Koenig K (2020) Effects of cupping therapy on Lower Quarter Y-Balance Test scores in collegiate baseball players. Research \& Investigation in Sports Medicine 6(1): 466468.

3. Arce-Esquivel A, Warner B, Gallegos D, Cage SA (2017) Effect of dry cupping therapy on vascular function among young individuals. International Journal of Health Sciences 5(3): 10-15.

4. Cao H, Li X, Yan X, Wang N, Bensoussan A, et al. (2014) Cupping therapy for acute and chronic pain management: A systematic reviewof randomized clinical trials. Journal of Traditional Chinese Medical Sciences 1(1): 49-61.

5. Futterman M, Bachman R (2016) Michael Phelps leads Rio cupping craze. The Wall Street Journal, New York, USA.

6. Lyons K (2016) Interest in cupping therapy spikes after Michael Phelps gold win. The Guardian, London, UK.

7. Cao H, Li X, Liu J (2012) An updated review of the efficacy of cupping therapy. PLos ONE 7(2).
8. Cage SA, Warner BJ, Gallegos DM (2020) Effect of cupping therapy on skin surface temperature in healthy individuals. Journal of Sports Medicine and Allied Health Sciences 5(3).

9. Chi L, Lin L, Chen C, Wang S, Lai H, et al. (2016) The effectiveness of cupping therapy on relieving chronic neck and shoulder pain: A randomized controlled trial. Evid Based Complement Alternat Med.

10. Liu W, Piao S, Meng X, Wei L (2013) Effects of cupping on blood flow under the skin of back in healthy human. World Journal of AcupunctureMoxibustion 23(3): 50-52.

11. Lowe D (2017) Cupping therapy: An analysis of the effects of suction on the skin and possible influence on human health. Complement Ther Clin Pract 29: 162-168.

12. Cage SA, Warner BJ, Gallegos DM, Winkelmann ZK (2020) Athletic trainers' perceived and actual knowledge of cupping therapy concepts. Journal of Sports Medicine and Allied Health Sciences 5(3).

13. Yang CW, Yen ZS, McGowan JE, Chen HC, Chiang WC, et al. (2012) A systematic review of retention of adult advanced life support knowledge and skills in healthcare providers. Resuscitation 83(9): 1055-1060.

14. Schellhase K, Plant J, Rothschild C (2015) Collegiate athletic trainers' perceived and actual knowledge of therapeutic ultrasound concepts. International Journal of Athletic Therapy and Training 20(5): 43-53. 